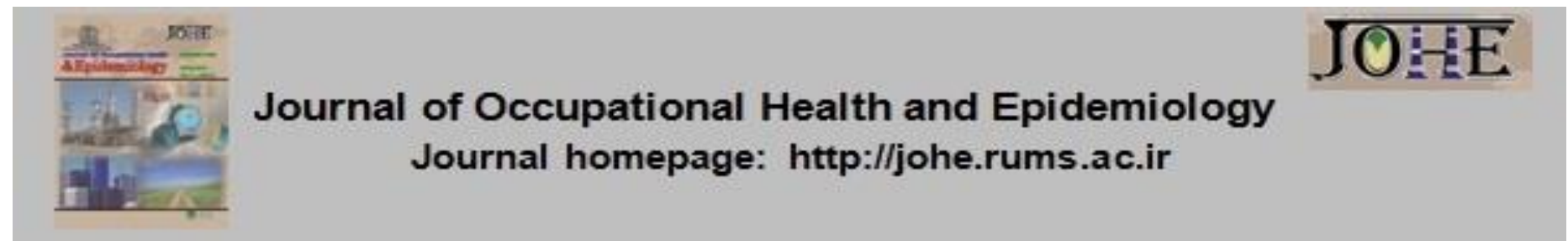

\title{
Population Size Estimation of Students with High-Risk Behaviors Using the Network Scale-up Method in Rafsanjan University of Medical Sciences, Iran (2017)
}

\author{
Sahar Peykani ${ }^{1}$, Ensieh Gheirati ${ }^{2}$, Mohsen Rezaeian $^{3}$, Reza Vazirinejad $^{4}$, Hassan Ahmadinia ${ }^{*}$ \\ 1. MSc in Epidemiology, Dept. of Epidemiology and Biostatistics, School of Medicine, Rafsanjan University of Medical Sciences, \\ Rafsanjan, Iran. \\ 2. MSc in Epidemiology Dept. of Epidemiology and Biostatistics, School of Public Health, Tehran University of Medical Sciences, \\ Tehran, Iran. \\ 3. Professor, Dept. of Epidemiology and Biostatistics, Occupational Environmental Research Center, School of Medicine, Rafsanjan \\ University of Medical Sciences, Rafsanjan, Iran. \\ 4. Professor, Dept. of Epidemiology and Biostatistics, Social Determinants of Health Research Center, Rafsanjan University of \\ Medical Sciences, Rafsanjan, Iran. \\ 5. Assistant Prof., Dept. of Epidemiology and Biostatistics, Occupational Environmental Research Center, School of Medicine, \\ Rafsanjan University of Medical Sciences, Rafsanjan, Iran.
}

Citation: Peykani S, Gheirati E, Rezaeian M, Vazirinejad R, Ahmadinia H. Population Size
Estimation of Students with High-Risk Behaviors Using the Network Scale-up Method in
Rafsanjan University of Medical Sciences, Iran (2017). J Occu Health Epidemiol 2021;
10(4):239-48.

\section{Article Info}

* Corresponding author: Hassan Ahmadinia,

E-mail:

H.ahmadinia@gmail.com

\section{Article history}

Received: Jul 2021

Accepted: Dec 2021

10.52547/johe.10.4.239

Print ISSN: 2251-8096 Online ISSN: 2252-0902

Peer review under
responsibility of Journal of
Occupational Health and
Epidemiology
Epidemiology

\section{Abstract}

Background: To manage a problem, knowing the size of the population associated is of great significance. In this study, direct and indirect (network scale-up [NSU]) methods were used to estimate the population size of students of the university of medical sciences with high-risk behaviors in Rafsanjan, Iran.

Materials \& Methods: In this cross-sectional study, using stratified random sampling, 440 students were selected and interviewed from the target group by a standard questionnaire, with three social network size estimation, NSU, and direct methods. The frequency approach of the NSU method was used to estimate the size of groups with high-risk behaviors. Correction coefficients were applied to adjust common errors in this method.

Results: Using the maximum likelihood method, the means of social network size $(C)$ for male and female students were 25.71 and 24.45 , respectively. Using the NSU method, the prevalence rates of alcohol drinking, extra-marital sexual relationship, and opium use were $26.57 \%, 15.28 \%$, and $9.69 \%$ among male students and $3.13 \%, 2.89 \%$, and $1.3 \%$ among female students, respectively. Using the direct method, the prevalence rates of alcohol drinking, extra-marital sexual relationship, and opium use were $23.2 \%, 14.3 \%$, and $6.25 \%$ among male students and $2.1 \%, 2.8 \%$, and $0.34 \%$ among female students, respectively.

Conclusions: Our results showed high-risk behaviors to have a relatively high prevalence among students of Rafsanjan University of Medical Sciences (RUMS). These behaviors were more prevalent among males than females. Thus, it seems necessary to plan preventative measures against drug abuse in academic departments.

Keywords: Social Network, High-Risk Behaviors, Students, Alcohol Drinking, Opium, Extramarital Sex Behavior.

\section{Introduction}

High-risk behaviors are hazardous that can cause physical, mental, and social problems and diseases at present or in the future. These behaviors include smoking, alcohol consumption, 
use of illicit and unauthorized drugs, and high-risk sexual behaviors [1].

One of the most important high-risk behaviors is substance abuse, a phenomenon with a worldwide prevalence that threatens humans as a critical social problem [2]. The use of illicit drugs is increasing among young people in many countries. The adverse consequences of using such drugs include dependence, excessive consumption, physical and psychological harms, and premature death [3].

According to unofficial estimates of the United Nations International Drug Control Program (UNDCP), the annual rate of drug abuse is about $3.3-4.1 \%$ of the world's total population. Drug abuse, alcohol consumption, and extra-marital affairs account for $2 \%, 8 \%$, and $5 \%$ of the world's disability-adjusted life year (DALY) among the age group of 15 to 24 years. According to the 2014 World Health Organization report, in 2010, the average per capita consumption of alcohol in Iran was zero; however, according to unofficial estimates, the average per capita alcohol consumption was estimated at 1 liter per year. According to the report, alcohol consumers in Iran are less than $0.1 \%$ of the total population (both genders). According to the unofficial statistics, per capita consumption amounts of alcohol are 26.9 liters and 17.8 liters per year for male and female regular consumers, respectively [4-5].

The phenomenon of drug addiction and its associated individual-social problems have inflicted the Iranian society for years. Due to bordering with the major opium-producing countries, Iran is considered one of the main routes of drug trafficking [6]. It also has become an appropriate market for the consumption of narcotics produced in Afghanistan [7]. In Iran, at least 2 million people consume illicit drugs, and 8 million households are directly faced with drug-related problems. The annual economic costs of illicit drugs amount to 10 trillion tomans [6]. Drug abuse also puts people at risk of HIV.

Although injecting drug users are still the most important group at risk for HIV transmission in the Iranian community, the ever-increasing role of high-risk sexual behaviors in the HIV epidemic in Iran should not be taken for granted [8-10]. Today, the youth are the greatest at-risk and vulnerable group, and the age of infection with this disease has witnessed a marked decline in recent years [11]. One of the issues that hinder a global response to HIV/AIDS is the collection of credible information about high-risk populations. Data collection is a challenging task due to the high HIV/AIDS risk in drug users, prostitutes, and homosexual men, and it is not possible to use a standardized statistical method for sample selection [12]. Given the structure of the young population in Iran and the high proportion of university students, as well as considering the fact that students constitute a large percentage of drug users, more serious studies are required. This issue is of great significance since students have different needs and motives [13], and they are young and active members of the society.

Entering university provides an opportunity for selfdetermination, independence, avoidance of family control, and management of sexual relations and sexual orientation. During this period, peer pressure influences individuals to abuse alcohol and drugs [14, 15]. The damage caused by highrisk behaviors in this stratum imposes harmful societal effects. Therefore, it is necessary to study this problem in this group of people; also, accurate statistics are required for planning to prevent these harms in this high-risk population. In different studies, the prevalence of drug abuse varies among students. In studies focusing on students, the rate of alcohol consumption has been reported to range between $5.7 \%$ and $38 \%$, and the rate of chronic alcohol consumption has been estimated at $7.1 \%$ to $8.3 \%$ [16].

In Tehran, Iran, the prevalence of opium use is 8$21 \%$, and that of high-risk sexual intercourse in the age group of 15 to 18 years is $28 \%$ [17]. Since there is a lack of planning regarding drug addiction, careful examination of its prevalence in the society is required. On the other hand, drug addiction and other high-risk behaviors are considered taboos in Iran, making the accurate estimation of their prevalence challenging. Accordingly, for obtaining statistics on the prevalence of high-risk behaviors, population estimation methods are used.

The use of indirect methods, including the network scale-up (NSU), for estimating hidden populations has been a very hot topic in recent years [18]. Due to the underestimations in direct studies, the NSU method is used as a complementary and costeffective strategy to estimate the prevalence of high-risk behaviors in communities. Due to the sensitivity of the role of students in our society, as well as the lack of studies on this issue in Rafsanjan, we decided to provide a more precise estimation of high-risk behaviors among students of RUMS through direct and indirect (NSU) methods.

\section{Materials and Methods}

This cross-sectional study was conducted on 1986 students in Rafsanjan University of medical science (RUMS) as the target group in 2017. Using 
Cochran's formula (Formula 1), based on a 1.5\% acceptable margin of error for proportion being estimated and the $3 \%$ prevalence of drug abuse in Iran [19], the sample size was estimated at 400 individuals. Considering $10 \%$ attrition, 440 questionnaires were completed.

\section{Formula 1.}

$$
\begin{gathered}
n_{0}=\frac{Z^{2} p q}{d^{2}}=\frac{1.96^{2} \times .03 \times(1-.03)}{0.015^{2}}=496.85, \\
n=\frac{n_{0}}{1+\frac{n_{0}}{N}}=\frac{496.85}{1+\frac{496.85}{1986}}=398, \quad q=1-p
\end{gathered}
$$

Third-semester and higher students were the inclusion criteria because they had the opportunity to familiarize themselves with the university campus and connect closely with others. Answering the questions was optional, and the incompleteness of the questionnaire was the exclusion criterion.

The students of RUMS were categorized into three strata based on the education level (1. Associate's and Bachelor's degrees, 2. Master's degrees, and 3. PhD degrees). In every stratum, only thirdsemester and above students were considered for selecting samples.

Sample selection was carried out proportionate to the overall population of each stratum, i.e., approximately $89 \%$ of the participants were undergraduates, and the rest were graduates. The participants were chosen using the random number table and the list of student IDs. Selected individuals who refused to participate in the study were replaced by fellow students.

A trained researcher presented the study goals at classes, and after obtaining informed consent, data was collected from the respondents by a standard questionnaire (Network Scale-Up Questionnaire) [17]. The students were asked to answer the questions separately.

The questionnaire included three sections. The first section covered demographic items on gender, age, the field of study, the year of starting the university, marital status, place of residence (dormitory or not), degree program, and indigenousness or non- indigenousness. The second section was to estimate the extent of the group with high-risk behaviors. It included A) 2 items to identify the extent of the interviewees' social network: according to the definition of cognition, how many female students do you know in RUMS? And how many male students do you know in RUMS? In this study, cognition is defined as a student of Rafsanjan University of Medical
Sciences whom you know by name and face, they also know you by name and face, you have had phone or email contact at least once in the past year, and you can contact them easily at any time required, and B) 8 items to determine the number of students with high-risk behaviors in the interviewee's personal network (for example, how many people do you know who drink alcohol?) Finally, the third section with 3 items aimed to estimate the size of the groups with high-risk behaviors through the direct method. Participants were directly asked about their own risky behaviors in the past year.

In this study, validity was approved by 4 experienced faculty members of the Epidemiology Department of Kerman and Rafsanjan. To allocate the reliability and internal consistency of the questionnaire, a pilot of 40 individuals was performed before sample selection, and Cronbach's alpha was estimated at 0.747. By following sample selection, Cronbach's alpha was calculated at 0.83 using data of 400 students.

The network scale-up (NSU) method: This method was first used in 1986 to estimate the number of missing individuals of the Mexico earthquake [19, 20]. It was invented in collaboration with anthropologists, social networking experts, and mathematicians [19]. The method can be used for telephone and face-to-face interviews using standardized questionnaires [19]. The first component in the NSU method is the determination of the individual's social network (active network), which is shown by the letter $C$ in calculations [19, 21]. For the determination of $C$, the four methods of frequency, probabilistic, direct, and indirect are used [19, 22]. Herein, we used the direct method to determine $\mathrm{C}$.

The direct method for determining C: In this case, the respondents are asked about the number of people they know in their active network (it is possible to narrow down the questions, and ultimately, add up all the people together to estimate the size of the social network; for example, how many old classmates do you know, or how many neighbors do you know. Then, by adding them up, the size of the active social network is obtained) [21, 22].

Using the direct method to determine the size of an active social network, whether general or in chunks, can be problematic. In fact, in the general question approach, recalling and enumerating the people each person knows is very difficult, and if the question is chunked down, there is a chance of repeating some people in several sub-groups. Similar studies have indicated that about $20 \%$ of the social network is missed using the direct 
method [19].

The definition of known population: The individuals introduced by the respondent should have made at least one telephone contact or sent an email throughout the past year, the respondent should know the individual by name and face, the individual should also know the respondent, and it should be possible to contact them easily at any time required [12, 19, 22-25].

Estimation of hidden groups: Estimation of hidden groups is performed using three methods. In the first method (probable), individuals are asked whether they know someone based on the provided definition involved with a problem we are looking for (for example, alcohol consumption); in this case, the answer is yes or no. In the second method, the case of the high frequency of positive answers, the participants are asked about the number of people they know. The third method is the maximum likelihood (ML) [19]. We used the third method in our study as follows.

Estimation of the size of the population with highrisk behaviors:

Stage one, estimating the average size of each student's social networks: The numbers mentioned by the students in the first two questions were used for estimating the size of each student's personal network using SPSS software, the maximum likelihood (ML) method, and 95\% confidence interval.

Stage two, estimating the average size of the total social network of students $C$ ) The figure obtained in the first stage, calculated for each student, was averaged to estimate the total social network size of Rafsanjan medical students.

Stage three, determining the number of people in the high-risk population each student knows. e) According to the answers given to the eight questions of the second part of the questionnaire $(\mathrm{m})$, the $\mathrm{C}$ number calculated in the previous stage, and the total student population of RUMS $(T=1986)$, e was calculated using the following formula [17].

\section{Formula 2}

$$
e_{j}={ }^{T \cdot m_{j}} / c
$$

Stage four, calculating the population size with high-risk behaviors M) Given the values obtained in previous stages and placing them in the formula, the size of the population with high-risk behaviors was estimated.

Given that the network expansion method has some limitations, it should be noted that the accuracy of this study depends on the validity of these assumptions. First, all members of the $T$ population have an equal chance to know the size of the groups under investigation. Second, everyone has full information about their acquaintances. Third, the participants remember the number of their acquaintances accurately and in a short time. These three conditions include barrier effect, transmission error, and estimation effects, respectively [23, 26].

Stage five, eliminating the effect of the common errors in the network expansion method: The crude size of the population as calculated in the fourth stage was adjusted using the following formula and the specific correction coefficients derived from by Maghsoudi et al., in Kerman in 2014, to determine the effect of the common errors [18].

\section{Formula 3.}

Adjusted Estimation $=$ Crude Estimation $\times(1 /$ Popularity Ratio $) \times(1 /$ Transmission Rate $)$

\section{Results}

Forty questionnaires were excluded because of zero or unacceptably large social networks. Accordingly, data analysis was on the data of 400 students. Of the studied students, 345 were under the age of $25(86.1 \%), 44(11.1 \%)$ aged $25-35$ years old, $8(2 \%)$ were within the age group of 36 45 years, and $3(0.8 \%)$ were over the age of 45 . The mean age of the students was $23.14 \pm 4.60$ years. The minimum and maximum ages were 19 and 50 years, respectively. Overall, $288(72.0 \%)$ of the participants were female, $304(76.0 \%)$ were single, $239(59.8 \%)$ were staying in dormitory, and $222(56.8 \%)$ were non-indigenous. Further, 247 $(61.7 \%)$ individuals were associate's and bachelor's students, 3.3\% were master's students, and $35 \%$ were $\mathrm{PhDs}$. In addition, 36 students were studying midwifery, 23 environmental health, 18 public health, 28 nursing, 47 anesthesiology, 103 medicine, 4 biochemistry, 1 internal surgery, 33 radiology, 32 laboratory sciences, 1 anatomy, 2 immunology, 1 epidemiology, 38 dentistry, 15 oral and dental health, and 18 medical emergencies.

Calculation of mean social network $C$ Using the maximum likelihood method, the size of the social network $C$ was calculated. The mean $C$ values calculated for men and women were 25.70 and 24.35 , respectively. Because of the conditions described in the definition of known population, we could estimate the presence of men in women's social networks and vice versa. Each female student was associated with an average of 6.90 men and 17.65 women, and each male student had contact with an average of 17.69 male and 
8.39 female university students. The estimated according to gender is presented in Tables 1 and size of populations with high-risk behaviors 2.

Table 1. Crude and Adjusted Estimates of Risky Behaviors among students of RUMS in 2017 Based on Women's Report

\begin{tabular}{|c|c|c|c|c|c|c|}
\hline $\begin{array}{c}\text { Risky } \\
\text { behavior }\end{array}$ & $\begin{array}{l}\text { Gender in the } \\
\text { social network }\end{array}$ & $\begin{array}{c}\text { Crude } \\
\text { (average count) }\end{array}$ & $\begin{array}{l}\text { Popularity } \\
\text { ratio }\end{array}$ & $\begin{array}{c}\text { Transmission } \\
\text { rate }\end{array}$ & $\begin{array}{c}\text { Adjusted } \\
\text { (average count) }\end{array}$ & $\begin{array}{c}\text { Prevalence } \\
(\%)^{*}\end{array}$ \\
\hline \multirow{3}{*}{ Alcohol } & Male & 20.15 & \multirow{3}{*}{0.9} & \multirow{3}{*}{0.45} & 49.75 & 3.97 \\
\hline & Female & 9.15 & & & 22.59 & 1.80 \\
\hline & Overall & 25.17 & & & 62.14 & 3.13 \\
\hline \multirow{3}{*}{ Opium } & Male & 12.68 & \multirow{3}{*}{0.9} & \multirow{3}{*}{0.45} & 31.30 & 2.49 \\
\hline & Female & 0.98 & & & 2.41 & 0.19 \\
\hline & Overall & 10.49 & & & 25.90 & 1.30 \\
\hline \multirow{3}{*}{$\begin{array}{l}\text { Sap of } \\
\text { opium }\end{array}$} & Male & 11.19 & \multirow{3}{*}{0.9} & \multirow{3}{*}{0.45} & 27.62 & 2.20 \\
\hline & Female & 0.0 & & & 0.0 & 0.0 \\
\hline & Overall & 8.28 & & & 20.44 & 1.03 \\
\hline \multirow{3}{*}{ Cannabis } & Male & 9.32 & \multirow{3}{*}{0.85} & \multirow{3}{*}{0.45} & 24.36 & 1.94 \\
\hline & Female & 0.0 & & & 0.0 & 0.0 \\
\hline & Overall & 6.9 & & & 18.03 & 0.91 \\
\hline \multirow{3}{*}{ Heroin } & Male & 3.73 & \multirow{3}{*}{0.96} & \multirow{3}{*}{0.54} & 7.19 & 0.57 \\
\hline & Female & 0.0 & & & 0.0 & 0.0 \\
\hline & Overall & 2.76 & & & 5.32 & 0.26 \\
\hline \multirow{3}{*}{ IDU** } & Male & 2.23 & \multirow{3}{*}{0.96} & \multirow{3}{*}{0.54} & 4.30 & 0.34 \\
\hline & Female & 0.24 & & & 0.46 & 0.03 \\
\hline & Overall & 1.93 & & & 3.72 & 0.18 \\
\hline \multirow{3}{*}{ Other } & Male & 16.04 & \multirow{3}{*}{ - } & \multirow{3}{*}{-} & - & - \\
\hline & Female & 2.96 & & & - & - \\
\hline & Overall & 15.19 & & & - & - \\
\hline \multirow{3}{*}{ EMS $^{\star \star \star}$} & Male & 23.59 & \multirow{3}{*}{1} & \multirow{3}{*}{0.44} & 53.61 & 4.27 \\
\hline & Female & 6.95 & & & 15.79 & 1.2 \\
\hline & Overall & 25.22 & & & 57.31 & 2.89 \\
\hline
\end{tabular}

*Estimating the prevalence of latent behavior in the target population, ${ }^{* *}$ Intravenous drug use; ${ }^{* *}$ Extra-marital sex

Table 2. Crude and Adjusted Estimates of Risky Behavior among students of RUMS in 2017 Based on Men's Report

\begin{tabular}{|c|c|c|c|c|c|c|}
\hline $\begin{array}{c}\text { Risky } \\
\text { behavior }\end{array}$ & $\begin{array}{l}\text { Gender in the } \\
\text { social network }\end{array}$ & $\begin{array}{c}\text { Crude } \\
\text { (average count) }\end{array}$ & $\begin{array}{l}\text { Popularity } \\
\text { ratio }\end{array}$ & $\begin{array}{c}\text { Transmission } \\
\text { rate }\end{array}$ & $\begin{array}{c}\text { Adjusted } \\
\text { (average count) }\end{array}$ & $\begin{array}{l}\text { Prevalence } \\
(\%)^{*}\end{array}$ \\
\hline \multirow{3}{*}{ Alcohol } & Male & 109.37 & \multirow{3}{*}{0.9} & \multirow{3}{*}{0.45} & 270.04 & 37.04 \\
\hline & Female & 10.86 & & & 26.81 & 3.67 \\
\hline & Overall & 213.33 & & & 525.74 & 26.57 \\
\hline \multirow{3}{*}{ Opium } & Male & 39.87 & \multirow{3}{*}{0.9} & \multirow{3}{*}{0.45} & 98.44 & 13.50 \\
\hline & Female & 4.07 & & & 10.04 & 1.37 \\
\hline & Overall & 77.83 & & & 192.17 & 9.69 \\
\hline \multirow{3}{*}{$\begin{array}{l}\text { Sap of } \\
\text { opium }\end{array}$} & Male & 28.10 & \multirow{3}{*}{0.9} & \multirow{3}{*}{0.45} & 69.38 & 9.51 \\
\hline & Female & 0.0 & & & 0.0 & 0.0 \\
\hline & Overall & 53.33 & & & 131.67 & 6.64 \\
\hline \multirow{3}{*}{ Cannabis } & Male & 36.88 & \multirow{3}{*}{0.85} & \multirow{3}{*}{0.45} & 96.41 & 13.22 \\
\hline & Female & 53.33 & & & 14.04 & 1.92 \\
\hline & Overall & 72.85 & & & 190.45 & 9.60 \\
\hline \multirow{3}{*}{ Heroin } & Male & 1.11 & \multirow{3}{*}{0.96} & \multirow{3}{*}{0.54} & 2.14 & 0.29 \\
\hline & Female & 0.0 & & & 0.0 & 0.0 \\
\hline & Overall & 2.12 & & & 4.08 & 0.20 \\
\hline \multirow{3}{*}{ IDU** } & Male & 8.57 & \multirow{3}{*}{0.96} & \multirow{3}{*}{0.54} & 16.53 & 2.26 \\
\hline & Female & 9.33 & & & 17.99 & 2.46 \\
\hline & Overall & 21.23 & & & 40.95 & 2.06 \\
\hline \multirow{3}{*}{ Other } & Male & 50.80 & \multirow{3}{*}{-} & \multirow{3}{*}{ - } & - & - \\
\hline & Female & 10.76 & & & - & - \\
\hline & Overall & 102.13 & & & - & - \\
\hline \multirow{3}{*}{$\mathrm{EMS}^{* * *}$} & Male & 57.34 & \multirow{3}{*}{1} & \multirow{3}{*}{0.44} & 130.31 & 17.87 \\
\hline & Female & 46.16 & & & 104.90 & 14.39 \\
\hline & Overall & 133.33 & & & 303.02 & 15.28 \\
\hline
\end{tabular}

${ }^{*}$ Estimating the prevalence of latent behavior in the target population, ${ }^{* *}$ Intravenous drug use; ${ }^{* * *}$ Extra-marital sex 
According to Table 1, the prevalence of alcohol consumption among female students was $1.80 \%$, while it was $3.97 \%$ among male students. The prevalence of extra-marital sexual affairs among female students was $1.2 \%$, and among male students, it was $4.27 \%$. Further, the prevalence of all the studied high-risk behaviors was higher in men than women. In men, the most commonly reported high-risk behavior was extra-marital sexual relationships with a prevalence of $4.27 \%$, followed by alcohol consumption with a prevalence of $3.97 \%$, opium use with a prevalence of $2.49 \%$, and sap consumption with a prevalence of $2.20 \%$. In women, the most commonly reported high-risk behaviors were alcohol consumption with a prevalence of $1.8 \%$, extra-marital sexual relationships with a prevalence of $1.2 \%$, and opium use with a prevalence of $0.19 \%$.

According to Table 2, the prevalence of alcohol consumption among female students was $3.67 \%$, and among male students, it was $37.04 \%$. The prevalence of extra-marital sexual affairs among female students was $14.39 \%$, while it was $17.87 \%$ among male students. Moreover, all the high-risk behaviors were more prevalent in men than women. Also, in men, the most common behaviors were alcohol consumption, extra-marital sexual relationships, and opium use. In women, the most commonly reported high-risk behaviors were extramarital sexual relationships with a prevalence of $14.39 \%$, alcohol consumption with a prevalence of $3.67 \%$, and injectable drug use with a prevalence of $2.46 \%$.

Table 3 shows that alcohol consumption was the most prevalent high-risk behavior $(9.62 \%)$ among the students of RUMS, followed by extra-marital sexual relationships and opium use with prevalence rates of $6.33 \%$ and $3.63 \%$, respectively. Over the past year, using the direct method, the prevalence of alcohol consumption among students of RUMS was $8 \%$, the prevalence of opium use was $2 \%$, and the consumption rate of other drugs was $3.75 \%$. The prevalence of extramarital relationships was estimated at $5.9 \%$ among the students.

Table 3. The overall prevalence of risky behaviors among students of RUMS in 2017

\begin{tabular}{cccccc}
\hline $\begin{array}{c}\text { Risky } \\
\text { behaviors }\end{array}$ & $\begin{array}{c}\text { No of students } \\
\text { with Risky behavior }\end{array}$ & $\begin{array}{c}\text { Prevalence } \\
(\%)\end{array}$ & $\begin{array}{c}\text { Crude } \\
\text { (average count) }\end{array}$ & $\begin{array}{c}\text { Adjusted } \\
\text { (average count) }\end{array}$ & $\begin{array}{c}\text { Prevalence } \\
\text { (\%) }\end{array}$ \\
\hline Alcohol & 32 & 8.0 & 77.28 & 190.81 & 9.62 \\
\hline Opium & 8 & 2.0 & 29.15 & 71.97 & 3.63 \\
\hline Sap of Opium & 4 & 1.0 & 20.76 & 51.25 & 2.58 \\
\hline Cannabis & 0 & 0.0 & 25.29 & 66.11 & 3.33 \\
\hline Heroin & 2 & 0.05 & 2.58 & 4.97 & 0.251 \\
\hline IDU & 0 & 0.0 & 7.35 & 14.17 & 0.715 \\
\hline Other & 15 & 3.75 & 39.44 & - & - \\
\hline EMS & 23 & 5.9 & 55.25 & 125.56 & 6.33 \\
\hline
\end{tabular}

*Estimating the prevalence of latent behavior in the target population, ${ }^{\star \star}$ Intravenous drug use; ${ }^{\star \star \star}$ Extra-marital sex

As presented in Table 4, the prevalence of alcohol consumption among single individuals was $11.41 \%$, and in married individuals, it was $4.01 \%$. The high-risk behaviors of alcohol and opium consumption were more common in single individuals. However, the prevalence of extramarital sexual affairs in married people was more than estimated. Alcohol consumption, extra-marital sexual relationships, and opium use were the most common high-risk behaviors in single individuals. In married individuals, the most commonly reported high-risk behaviors were extra-marital sexual affairs, with a prevalence of $7.29 \%$, followed by alcohol and opium use, respectively.

In indigenous students of Rafsanjan, the prevalence of alcohol consumption was $8.92 \%$, the prevalence of extra-marital relationships was $6.46 \%$, and the prevalence of opium use was $2.61 \%$, which were the most commonly reported high-risk behaviors, respectively. In non- indigenous students in Rafsanjan, the overall prevalence of alcohol consumption was $9.42 \%$, the prevalence of extra-marital relationships was $6.21 \%$, and the prevalence of opium use was $3.29 \%$, which were the most commonly reported high-risk behaviors, respectively. In dormitory students, the prevalence rates of alcohol consumption, extra-marital relationships, and opium use were $9.95 \%, 7.97 \%$, and $2.41 \%$, respectively. In non-dormitory students, the prevalence rates of alcohol abuse, opium use, and extra-marital relationship were $7.66 \%, 4.28 \%$, and $3.62 \%$, respectively, which were the most commonly reported high-risk behaviors, respectively. The highest prevalence of alcohol consumption (16.36\%), extra-marital relationship $(11.51 \%)$, and opium use $(8.18 \%)$ were observed in doctoral students. However, the lowest prevalence of high-risk behaviors was observed in master's students. 
Table 4. Prevalence of risky behaviors in terms of demographic variables among students of RUMS in 2017

\begin{tabular}{|c|c|c|c|c|c|c|c|}
\hline \multirow{2}{*}{\multicolumn{2}{|c|}{ Demographic variables }} & \multirow[b]{2}{*}{$\begin{array}{c}\text { Risky } \\
\text { behaviors }\end{array}$} & \multicolumn{2}{|c|}{ Direct method } & \multicolumn{3}{|c|}{ NSU method } \\
\hline & & & $\begin{array}{c}\text { No of students } \\
\text { with Risky } \\
\text { behavior }\end{array}$ & $\begin{array}{c}\text { Prevalence } \\
(\%)\end{array}$ & $\begin{array}{c}\text { Crude } \\
\text { (Average } \\
\text { count) }\end{array}$ & $\begin{array}{c}\text { Adjusted } \\
\text { (Average } \\
\text { count) }\end{array}$ & $\begin{array}{c}\text { Prevalence } \\
(\%)^{\star}\end{array}$ \\
\hline \multirow{6}{*}{ Gender } & \multirow{3}{*}{ Male } & Alcohol & 26 & 23.2 & 25.17 & 190.81 & 3.13 \\
\hline & & Opium & 7 & 6.25 & 10.49 & 71.97 & 1.30 \\
\hline & & $E^{\prime} M S^{* *}$ & 16 & 14.3 & 25.22 & 125.56 & 2.89 \\
\hline & \multirow{3}{*}{ Female } & Alcohol & 6 & 2.1 & 213.33 & 190.81 & 26.57 \\
\hline & & Opium & 1 & 0.3 & 77.83 & 71.97 & 9.69 \\
\hline & & EMS $^{* *}$ & 8 & 2.8 & 133.33 & 125.56 & 15.28 \\
\hline \multirow{6}{*}{$\begin{array}{l}\text { Marital } \\
\text { status }\end{array}$} & \multirow{3}{*}{ Single } & Alcohol & 30 & 9.9 & 91.65 & 190.81 & 11.41 \\
\hline & & Opium & 8 & 2.6 & 35.03 & 71.97 & 4.36 \\
\hline & & EMS $^{* *}$ & 24 & 7.9 & 52.58 & 125.56 & 6.02 \\
\hline & \multirow{3}{*}{ Married } & Alcohol & 2 & 2.0 & 32.20 & 190.81 & 4.01 \\
\hline & & Opium & 0 & 0.0 & 10.73 & 71.97 & 1.33 \\
\hline & & EMS $^{* *}$ & 0 & 0.0 & 63.58 & 125.56 & 7.29 \\
\hline \multirow{6}{*}{ Native or not } & \multirow{3}{*}{ Yes } & Alcohol & 10 & 6.0 & 71.63 & 190.81 & 8.92 \\
\hline & & Opium & 3 & 1.8 & 21.01 & 71.97 & 2.61 \\
\hline & & EMS $^{* *}$ & 9 & 5.4 & 56.35 & 125.56 & 6.46 \\
\hline & \multirow{3}{*}{ No } & Alcohol & 21 & 9.5 & 75.65 & 190.81 & 9.42 \\
\hline & & Opium & 5 & 2.25 & 26.42 & 71.97 & 3.29 \\
\hline & & EMS $^{* *}$ & 12 & 5.4 & 54.18 & 125.56 & 6.21 \\
\hline \multirow{6}{*}{$\begin{array}{c}\text { Dormitory or } \\
\text { not }\end{array}$} & \multirow{3}{*}{ Yes } & Alcohol & 20 & 8.4 & 79.94 & 190.81 & 9.95 \\
\hline & & Opium & 6 & 2.5 & 19.40 & 71.97 & 2.41 \\
\hline & & EMS $^{* *}$ & 12 & 5.0 & 69.53 & 125.56 & 7.97 \\
\hline & \multirow{3}{*}{ No } & Alcohol & 11 & 7.6 & 61.53 & 190.81 & 7.66 \\
\hline & & Opium & 2 & 1.38 & 34.37 & 71.97 & 4.28 \\
\hline & & EMS $^{* *}$ & 8 & 5.6 & 31.6 & 125.56 & 3.62 \\
\hline \multirow{9}{*}{ Degree } & \multirow{3}{*}{ BSc } & Alcohol & 15 & 6.07 & 51.58 & 190.81 & 6.42 \\
\hline & & Opium & 7 & 2.83 & 9.69 & 71.97 & 1.20 \\
\hline & & EMS $^{* *}$ & 12 & 4.85 & 33.58 & 125.56 & 3.85 \\
\hline & \multirow{3}{*}{ MSc } & Alcohol & 1 & 7.7 & 36.59 & 190.81 & 4.55 \\
\hline & & Opium & 0 & 0.0 & 12.19 & 71.97 & 1.51 \\
\hline & & EMS $^{* *}$ & 0 & 0.0 & 18.29 & 125.56 & 2.09 \\
\hline & \multirow{3}{*}{ PhD } & Alcohol & 16 & 11.4 & 131.37 & 190.81 & 16.36 \\
\hline & & Opium & 1 & 0.71 & 65.68 & 71.97 & 8.18 \\
\hline & & EMS $^{* *}$ & 12 & 8.6 & 100.38 & 125.56 & 11.51 \\
\hline
\end{tabular}

*Estimating the prevalence of latent behavior in the target population, ${ }^{* *}$ Extra-marital sex

Over the past year, using the direct method, the prevalence of alcohol consumption among female students in Rafsanjan University of Medical Sciences was $2.1 \%$, and in male students, it was $23.2 \%$. All the high-risk behaviors in male students were more prevalent. The prevalence of alcohol consumption among single students of Rafsanjan University of Medical Sciences was $9.9 \%$, and in married students, it was $2.1 \%$. All the high-risk behaviors were more common in single students. The prevalence of alcohol consumption in indigenous students was $6 \%$, and in nonindigenous students, it was $9.5 \%$. All the high-risk behaviors were more common in non-indigenous students. The prevalence of alcohol consumption in dormitory students was $8.4 \%$, and in nondormitory students, it was $7.6 \%$. All the high-risk behaviors were more common in dormitory students. The prevalence of alcohol consumption in associate's and bachelor's students was $6.07 \%$, and in master's students, it was $7.7 \%$. Further, in doctoral students, the prevalence of this behavior was $11.4 \%$. All the high-risk behaviors were more common in doctoral students.

\section{Discussion}

The outbreak of the COVID-19 pandemic has caused a global crisis of general and mental health, as well as a huge psychosocial experience [28]. This study examined the psychological consequences (including general health, general anxiety disorder, and post-traumatic stress disorder) of the COVID-19 disease in physicians and medical students during its outbreak. The results reflected the psychological effects of the COVID-19 pandemic on the mental health of the who groups in Iran.

Based on the results, the scores of almost half of physicians and medical students participating in this study were higher than the threshold of the GHQ, indicating significant mental health problems. In addition, the highest score was related to the dimension of social functioning, and 
the lowest score was related to the dimension of depression, so that $73.5 \%$ of the participants had social dysfunction. These results have been confirmed in studies on the prevalence of the disease in Iranian society [29-31] and other communities [10, 11]. Disturbance of individual structures reduces control of the individual and the predictability of the flow of life [32]. Hence, social support reduces anxiety and stress and improves self-efficacy [33]. Socioemotional support and empathy of friends or family members can help medical staff reduce anxiety [34]. Social support can help reduce stress by reducing the perception of threat from stressful events, resulting in the right physiological response [33].

Twenty-four-tenths of a percent of the participants in our study had symptoms of anxiety, which was higher than that in the studies of Rabih $\mathrm{H}$ et al. (United Arab Emirates) (19.8\%) [4] and Wei Deng et al. (21\%) [9] that were performed on the general population and healthcare workers. However, the anxiety symptom percentage in our study was lower than that in the study of Chang Jinghui [35] ( $28.9 \%$ mild, $11.5 \%$ moderate, and $7.4 \%$ severe). Numerous studies have examined the psychological implications of the COVID-19 pandemic on the mental health of students and physicians, particularly in China. Chang Jinghui \& et al. (2020) showed that $26.6 \%$ of the medical students in Guangdong Province, China, had anxiety symptoms, and $21.16 \%$ of them had symptoms of depression [35]. Furthermore, Wei Deng in China (2019) found that the prevalence of depression in medical students was $29 \%$ [9]. Naseem Ahmed (2020) examined the concerns of medical students about the prevalence of COVID19 and showed that $75.8 \%$ of participants were worried about the possibility of developing the disease and $80 \%$ of them were afraid of inadequate treatment and care [36].

Rabih Halvani in the United Arab Emirates showed that approximately half of the medical students reported varying degrees of anxiety, from mild to severe, during hospital visits [4]. Muhammad Salman et al. in Pakistan found that COVID-19 had a significant adverse impact on students' mental health [37].

Among the few studies on the psychological consequences of the COVID-19 outbreak among physicians, Civantos AM showed that $47.9 \%$ of the participants $(\mathrm{N}=349)$ were anxious $(28.9 \%$ mild, $11.5 \%$ moderate, $7.4 \%$ severe), and $21.8 \%$ were depressed. Furthermore, $60.2 \%$ of the physicians reported symptoms of distress (EIS) $(32.7 \%$ mild, $20.9 \%$ moderate, and $6.6 \%$ severe) [38]. Another study in China found that $11.4 \%$ and $45.6 \%$ of the physicians had symptoms of anxiety and depression, respectively [39]. A study in Iran found that $68.5 \%$ of the physicians caring for COVID-19 patients suffered from anxiety [40]. Anxiety is the most fundamental characteristic of critical situations, and the unpredictability of the future has the greatest role in creating it [41]. Therefore, it can negatively affect people's mental health. The results of this study showed that the COVID-19 pandemic had negative adverse effects on the health of psychiatrists and medical students in Iran.

The recent COVID-19 pandemic has features such as an unprecedented number of patients with severe and often unpredictable symptoms, high mortality, and lack of effective treatments that increase the risk of PTSD among medical students. PTSD is a severe mental illness that may develop in individuals who have experienced or witnessed a traumatic event [42]. Hence, the recent outbreak burden on medical students and physicians deserves much more attention because they are more likely to be involved in diagnosing and treating COVID-19 patients and more prone to mental disorders, including PTSD.

Thirty-three and three-tenths of a percent of the participants in our study had PTSD symptoms that were higher than that in the studies of Sen Chen in China [43] and Apostolos Blekas in Greece (43), which were performed on undergraduate student and healthcare workers. Such a discrepancy may be because the participants in this study had different levels of contact with the COVID-19 patients, possibly increasing the fear of transmitting the disease. Fear is an adaptive response to defensive behaviors to protect oneself from danger, which can be followed by PTSD when improperly adjusted [44]. Regarding the contagious nature of the COVID-19 and its long incubation period (14 days or more), many participants may be afraid of inadvertent contact with the disease and spreading it to other family members. Therefore, using continuing education to better understand the disease and how to decrease the risks of coronary heart disease can play an effective role in reducing the impact [45]. Also, it is helpful to perform psychological interventions to reduce fear of pandemics, induce psychological resilience, and prevent PTSD.

According to the results of this study, although there was no statistically significant difference between mental health disorder, age, and sex, the mental health disorder of women was higher than that of men, indicating that women usually have a higher rate of psychological distress than men. Because female students have less social support, they may suffer from a decreased sense of cohesion, which in turn is a strong explanatory 
variable for psychological distress in medical students in general and female students in particular [46]. In addition, the higher prevalence of mental disorders in female students than those of males can be due to biological factors, the role of gender, environmental stress, poor satisfaction, and limited social participation of girls in society. Other reasons include stress management methods in both sexes [47]. The results showed that among the study variables, only job was associated with psychological disorders. On the other hand, the risk of psychological disorders in medical students was 2.38 times higher than that of the physicians, which may be due to the greater work experience of the latter group in dealing with such situations.

One of the limitations of this study was the limited studies on the prevalence of depression, anxiety, and mental health disorders among medical students and physicians during the COVID-19 epidemic worldwide, and in particular, in the Middle East; thus, it was not possible to compare our findings with similar environments and cultures. In addition, the cross-sectional nature of this study did not allow us to determine the cause and effect relationship between psychological complications and stress. It may be helpful to repeat the study after the peak of the epidemic to determine the effect of time on results. Despite these limitations, the present study appears to be unique, which has used a standardized measure to quantify the mental health of medical students.

However, further studies on larger sample sizes are recommended to describe the causes, consequences, and solutions to these problems. Repeating these studies at other academic centers and conducting similar studies are other suggestions.

\section{Conclusion}

The findings of this study indicate a higher prevalence of all high-risk behaviors in men than women. These values are reported higher in the indirect method than that of the direct. Meanwhile, prevalence estimates using the indirect method and exclusively male social networks are exponentially higher and distinct from other subgroups. Also, the highest prevalence rate pertains to alcohol consumption, followed by extramarital affairs and opium use, which are similar in both gender groups. To identify the predisposing factors among students, especially males, performing further extensive studies is necessary. Additionally, more cohesive planning to design proper interventions such as student counseling and mental health centers at the university is mandatory to prevent such behaviors.

\section{Acknowledgement}

This project was derived from a master's thesis in Epidemiology, Rafasanjan University Medical Sciences. We wish to thank the students of Rafsanjan University of Medical Sciences, as well as Dr. Ali Akbar Haghdoost, for their cooperation. We would like to thank Dr. Mohammad Reza Baneshi for his guidance in data analysis. This study was supported by Rafsanjan University of Medical Sciences.

\section{Conflict of interest: None declared.}

\section{References}

1. Atashnafas E, Ghorbani R, Tabatabaee M, Abdoos H, Abbas Poor S, Mahmoudian AR. Prevalent High Risk Behaviors and Important Family Factors from the Point of View of Adolescents: A Qualitative Research. J Fam Stud 2014; 10(2):217-33.

2. Hosseni F. An Analysis Survey of Effective Factors on Addiction of Narcotic Drug in Order to Present Preventive Solutions. J Boushehr Police Sci 2012; 3(9):1-28.

3. Hillebrand J, Monterio M. Substance Use and Its Toll on Society. Common Health 2001; 9(1):9-13.

4. World Health Organization. Iran (Islami Republic of), Alcohol Consumption: Levels and Patterns. Geneva, Switzerland: World Health Organization; 2018.

5. Bagheri Lankarani K, Afshari R. Alcohol consumption in Iran. Lancet. 2014; 384(9958):1927-8.

6. Sarrami H, Ghorbami M, Taghavi M. The Survey Two Decades of Prevalence Studies among Iran University Students. Res Addict 2013; 7(27):9-36.

7. Tajdari A, Zakariayi MA. Indirect Methods of Estimating Drug User Population Size. J Social Proble Iran 2011; 1(4):11-29.

8. Haghdoost AA, Pourkhandani A, Motaghipisheh $S$, Farhoudi B, Fahimifar N, Sadeghirad B. Knowledge and Attitude Concerning HIV/AIDS among Iranian Population: A Systematic Review and Meta-Analysis. Epidemiol 2011; 6(4):8-20.

9. Azin S. An overview on the 2008 UNAIDS Report on the 2008 UNAIDS Report on the Global AIDS Epidemic. Epidemiol 2010; 6(2):56-9.

10. Vakilian K, Mousavi SA, Keramat A. Estimation of sexual behavior in the 18-to-24-years-old Iranian youth based on a crosswise model study. BMC Res Notes 2014; 7:28. 
11. Siyam S. Drug abuse prevalence between male students of different universities in Rasht in 2005. Zahedan J Res Med Sci 2007; 8(4):e94869.

12. Salganik MJ, Fazito $D$, Bertoni $N$, Abdo $A H$, Mello MB, Bastos FI. Assessing network scaleup estimates for groups most at risk of HIV/AIDS: evidence from a multiple-method study of heavy drug users in Curitiba, Brazil. Am J Epidemiol 2011; 174(10):1190-6.

13. Walker S, Cosden M. Reliability of college student self-reported drinking behavior. J Subst Abuse Treat 2007; 33(4):405-9.

14. Cooper ML. Alcohol use and risky sexual behavior among college students and youth: evaluating the evidence. J Stud Alcohol Suppl 2002; (14):101-17.

15. Deressa W, Azazh A. Substance use and its predictors among undergraduate medical students of Addis Ababa University in Ethiopia. BMC Public Health 2011; 11:660.

16. Babaei Heydarabadi A, Ramezankhani A, Barekati H, Vejdani M, Shariatinejad K, Panahi $\mathrm{R}$, et al. Prevalence of Substance Abuse among Dormitory Students of Shahid Beheshti University of Medical Sciences, Tehran, Iran. Int J High Risk Behav Addict 2015; 4(2):e22350.

17. Sheikhzadeh K, Baneshi MR, Afshari M, Haghdoost AA. Comparing direct, network scale-up, and proxy respondent methods in estimating risky behaviors among collegians. J Subst Use 2016; 21(1):9-13.

18. Maghsoudi A, Baneshi MR, Neydavoodi M, Haghdoost A. Network scale-up correction factors for population size estimation of people who inject drugs and female sex workers in Iran. PloS One 2014; 9(11):e110917.

19. Shokouhi M, Mohebbi E, Rastegari A, Hajimaghsoudi S, Haghdoost AA, Baneshi MR. The Introduction of Network Scale-up Method: An Indirect Method to Estimate the Hard-toReach Populations. Epidemiol 2014;10(1):8192.

20. Kadushin C, Killworth PD, Bernard HR, Beveridge AA. Scale-Up Methods as Applied to Estimates of Heroin Use. J Drug Issues 2006; 36(2):417-40.

21. Bernard HR, Hallett $T$, lovita $A$, Johnsen EC, Lyerla R, McCarty $C$, et al. Counting hard-tocount populations: the network scale-up method for public health. Sex Transm Infect 2010; 86(Suppl 2):ii11-5.

22. Shokoohi M, Baneshi MR, Haghdoost AA. Estimation of the active network size of Kermanian males. Addict Health 2010; 2(34):81-8.

23. Ezoe S, Morooka T, Noda T, Sabin ML, Koike S. Population size estimation of men who have sex with men through the network scale-up method in Japan. PloS One 2012; 7(1):e31184.
24. Shokoohi M, Baneshi MR, Haghdoost AA. Size Estimation of Groups at High Risk of HIV/AIDS Using Network Scale Up in Kerman, Iran. Int J Prev Med 2012; 3(7):471-6.

25. Dehghani K, Zare A, Dehghani $H$, Sedghi $H$, Poormovahed Z. Drug Abuse Prevalence and Risk Factors in Students of Shaheed Sadoughi University of Medical Sciences, Yazd. J Shahid Sadoughi Uni Med Sci 2010; 18(3):164-9.

26. Pisani E. Estimating the size of populations at risk for HIV: Issues and Methods. North Carolina, United States: Family Health International; 2003.

27. Heydari ST, Izedi S, Sarikhani Y, Kalani N, Akbary A, Miri A, et al. The Prevalence of Substance Use and Associated Risk Factors among University Students in the City of Jahrom, Southern Iran. Int J High Risk Behav Addict 2015; 4(2):e22381.

28. Hedayati-Moghaddam MR, EftekharzadehMashhadi I, Fathimoghadam F, Pourafzali SJ. Sexual and Reproductive Behaviors among Undergraduate University Students in Mashhad, a City in Northeast of Iran. J Reprod Infertil 2015; 16(1):43-8.

29. Randolph ME, Torres H, Gore-Felton C, Lloyd $B$, McGarvey EL. Alcohol use and sexual risk behavior among college students: understanding gender and ethnic differences. Am J Drug Alcohol Abuse 2009; 35(2):80-4.

30. Kazemzadeh Y, Shokoohi M, Baneshi MR, Haghdoost AA. The Frequency of High-Risk Behaviors among Iranian College Students Using Indirect Methods: Network Scale-Up and Crosswise Model. Int J High Risk Behav Addict 2016; 5(3):e25130.

31. Maghsoudi A, Jalali M, Neydavoodi M, Rastad $H$, Hatami I, Dehghan A. Estimating the prevalence of high-risk behaviors using network scale-up method in university students of Larestan in 2014. J Subst Use 2017; 22(2):1458.

32. Guo W, Bao S, Lin W, Wu G, Zhang W, Hladik $W$, et al. Estimating the size of HIV key affected populations in Chongqing, China, using the network scale-up method. PloS One 2013; 8(8):e71796.

33. Barbosa CDS, Stefanello CR, Dias MB, Beskow $\mathrm{MH}$, Hirdes É, Krüger EH, et al. Risk Factors for Illicit Drug Disorders during Adolescence: An Analysis According To Substance of Preference. J Subst Abuse Alcohol 2017;5(2):1057.

34. Mirzazadeh A, Shokoohi M, Navadeh $S$, Danesh A, Jain J, Sedaghat A, et al. Underreporting in HIV-related high-risk behaviors: comparing the results of multiple data collection methods in a behavioral survey of prisoners in Iran. Prison J 2018; 98(2):21328. 